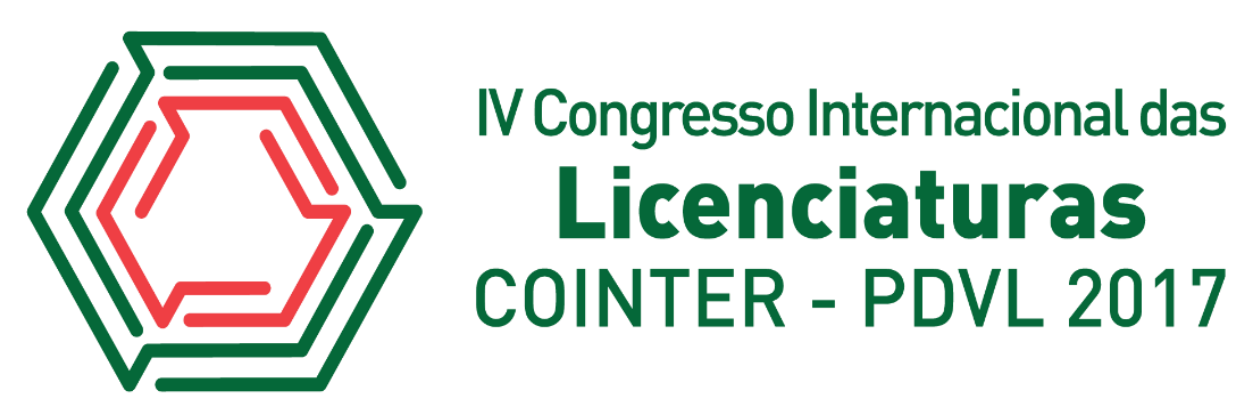

\title{
O GÊNERO TEXTUAL CHARGE COMO INSTRUMENTO METODOLÓGICO DE ENSINO E APRENDIZAGEM
}

Apresentação: Pôster

Vinicius Santos Oliveira ${ }^{1}$; Wanderson Felipe G. Marinho²; Elzilene de Sales Dias Nogueira ${ }^{3}$

\section{Introdução}

A proposta de inclusão de gêneros textuais como a charge na escola, é relacionado pelo objetivo de tornar a sala de aula um ambiente de leitura, debate e reflexão sobre a língua e a sociedade tornando o ambiente escolar um espaço dinâmico e significativo para os alunos. Dessa forma, devese fazer uso de métodos que contribuam para esse propósito provocando o interesse dos alunos e promovendo um processo de ensino e aprendizagem de língua portuguesa. Segundo Silva (2004, p.28):

[...] a oferta de leitura na escola se apresenta como círculo fechado, envolvendo somente as obras da chamada, Literatura pedagógica ${ }^{e e}$ (clássicos escolares). Por outro lado, além do esquema redundante da oferta, fechada à literatura de vanguarda e por isso mesmo reveladora, constatamos a presença de metodologias que ao invés de propiciar o prazer e o gosto pela leitura, vão paulatinamente aniquilando o potencial da leitura dos alunos.

O ensino, por sua vez, sempre está em constante transformação e necessita de processos de organização, de uma relação mais próxima da teoria com a prática onde possa existir uma aprovação cientifica ou gerenciamentos dos processos de aprendizagem que venham a ser apresentados com estratégias didáticas desenvolvidas em sala de forma a enriquecer o conteúdo estudado.

A experiência educativa tenta ressignificar as práticas de leitura com uso de tecnologias e também o de desenvolver práticas pedagógicas que ajudem o professor a se integrar mais de forma significativa e motivadora em sua construção docente, atuando de forma autônoma e prazerosa, propiciando ao seu meio profissional um papel participativo e criativo. Segundo MORAN (2000):

“A produção do saber nas áreas do conhecimento leva o professor e o aluno a buscar

\footnotetext{
${ }^{1}$ Licenciando em Computação, IFTO- Campus Araguatins, viniciusxp.96@hotmail.com

${ }^{2}$ Licenciando em Ciências Biológicas, IFTO-Campus Araguatins, felipew.licbio@gmail.com

${ }^{3}$ Especialista em Letras, IFTO- Campus Araguatins, elzilene.dias@ifto.edu.br
} 
processos de investigação e pesquisa. O aluno precisa ser menos passivo e tornar-se criativo, crítico, pesquisador e atuante. $\mathrm{O}$ professor precisa agir com critério e com visão transformadora".

Sabe- se que a metodologia de ensino e aprendizagem consiste numa troca de saberes onde o professor/graduando atua como um intermediador entre seus alunos e o conhecimento, assim este processo consiste em educador- educando- conhecimento.

Portanto, o relato a seguir mostra as abordagens acerca do gênero textual charge destacando os métodos e práticas utilizadas no processo de ensino aprendizagem.

\section{Fundamentação Teórica}

A atenção ás novas modalidades de ensino requer que o profissional em educação viva em constantes mudanças no que diz respeito à sua maneira de ensinar. O gênero charge deve ser visto como uma ferramenta no qual conseguimos assimilar o desenvolvimento intelectual, motor e crítico para o educando e para o seu orientador, este que por sua vez deve atenuar-se aos benefícios que o seu ensino traz para as inovações na prática em sala de aula.

A charge é um gênero de texto que visa atrair o leitor por apresentar diversos aspectos do uso da língua, contemplando a linguagem verbal e não verbal, bem como a construção de sentidos.

\footnotetext{
"A charge engloba o verbal e o não-verbal como reforçadores na produção dos efeitos do sentido. Focalizando frequentemente a política, a charge pode apresentar-se em um único quadro ou em mais cenas com escritas representando as falas dos personagens em balões ou até mesmo sem nenhuma representação da escrita, apenas a imagem falando por si mesma" (TEIXEIRA, 2010, p. 96-97).
}

Dessa forma, o uso da língua baseia-se na utilização de suas formas, não se limitando apenas na palavra escrita ou falada. A charge possui ainda o acréscimo de imagens, as quais que dinamizam o processo de compreensão do texto escrito. Portanto, "é um gênero de rápida leitura, transmitindo múltiplas informações de condensada. Além da facilidade de leitura, o texto chárgico diferencia-se dos demais gêneros opinativos por fazer sua crítica usando constantemente o humor" (ROMUALDO, 2000, p. 05). Por essa razão, é um gênero indispensável na sala de aula.

$\mathrm{Na}$ charge, o contexto gira em torno de imagens que são compostas por desenhos nos quais estão inseridos em algum acontecimento. Assim, esse gênero busca expressar uma crítica irônica a certa de algum fato real.

"Seu objetivo é a crítica humorística de um fato ou de um acontecimento específico. É a reprodução gráfica de uma notícia já conhecida do público segundo a ótica do chargista. 
Tanto se apresenta somente através de imagens quanto combinando imagem e texto. Sua ocorrência opera em cima de fatos reais e o conhecimento prévio do tema abordado na charge, por parte do leitor, é fator essencial para compreendê-la" (ARBACH,2007).

\section{Metodologia}

Embora tenha se discutido bastante práticas de letramentos por vários teóricos do campo da linguística há muitos desafios ainda quando se trata de interpretação e compreensão textual neste campo. Por exemplo, muitos alunos ainda não aprenderam ler imagens e o que está por traz delas pelo fato de não exercerem o exercício da leitura valorizando os diferentes fatores de textualidade como: intertextualidade, situacionalidade. Essa pesquisa baseou- se em termos qualitativos e buscou a observação, a descrição, a compreensão e o significado dos conhecimentos adquiridos tanto dos os cursistas quanto dos os graduandos a partir das práticas metodológicas da oficina em questão. $\mathrm{O}$ presente trabalho tem o intuito de compartilhar as experiências vivenciadas na oficina ministrada na JINTER (Jornada Interdisciplinar), por alunos do curso de Licenciatura em Computação do IFTO (Instituto Federal de Educação, Ciência e Tecnologia do Tocantins Campus- Araguatins), onde o gênero textual charge foi apresentado em forma de oficina fazendo uso da ferramenta hipertexto com o objetivo de desenvolver práticas de letramentos através da Web. Esta atividade foi orientada pela Professora especialista Elzilene de Sales Dias Nogueira. A referida oficina teve como público alvo alunos das últimas séries do ensino fundamental e do Ensino Médio da rede estadual.

Por charge tratar- se de um gênero textual jornalístico que utiliza imagens/desenhos para expressar posicionamentos de forma irônica e crítica acerca das situações do cotidiano, iniciou-se a execução da oficina com a apresentações dos participantes e exposição de ilustrações de figuras das charges e seus contextos históricos para que os cursistas interagissem com os textos analisados. Logo após, deu- se início a apresentação sobre o gênero charge e suas características em slide. Paralela a apresentação, os acadêmicos direcionaram os alunos no contexto da charge com perguntas referente aos textos de forma dinâmica e interativa de modo que as habilidades e competências de leitura fossem sendo instigadas nos educandos (Figura 1). Após a dinâmica que foi mais expositiva, iniciouse o momento prático em que foram entregues aos participantes textos de notícias recentes com as quais os discentes tinham que desenvolver suas próprias charges, fazendo a síntese do que tinham aprendido na oficina. Durante a dinâmica era possível detectar se os alunos ativavam fatores 
importantes como conhecimentos prévios e situacionais para interpretação e compreensão dos textos observados.

\section{Resultados e Discussões}

A atividade proporcionou interatividade e subjetividade, isso trouxe retornos bastante positivos como o desejo pelos alunos cursistas de ler mais textos e participar espontaneamente durante o desenrolar da oficina. Como afirma PÉREZ GÓMEZ (1998), a participação estimula o saber.

"[...] facilitar e estimular a participação ativa e crítica dos alunos/as nas diferentes tarefas que se desenvolvem na aula e que constituem modo de viver da comunidade democrática de aprendizagem" (PÉREZ GÓMEZ, 1998, p.26).

Partindo deste pressuposto, os alunos tiveram a capacidade de desenvolver senso crítico e social de acontecimentos, baseando- se nas leituras interacionistas e no formato em que os textos foram apresentados lidos e discutidos. O gênero textual charge como qualquer outro, quando trabalhado de forma criativa e significativa desenvolve no aluno a criticidade, a maturidade de forma responsável e sustentável para a sociedade.

[...] para Vygotsky, o desenvolvimento do sujeito se dá a partir das constantes interações com o meio social em que vive, já que as formas psicológicas mais sofisticadas emergem da vida social. Assim, o desenvolvimento do psiquismo humano é sempre mediado pelo outro (outras pessoas do grupo cultural), que indica, delimita e atribui significados à realidade (REGO, 1997, p. 60-61).

Imagem 1: Atividade Experimental. Fonte: Própria

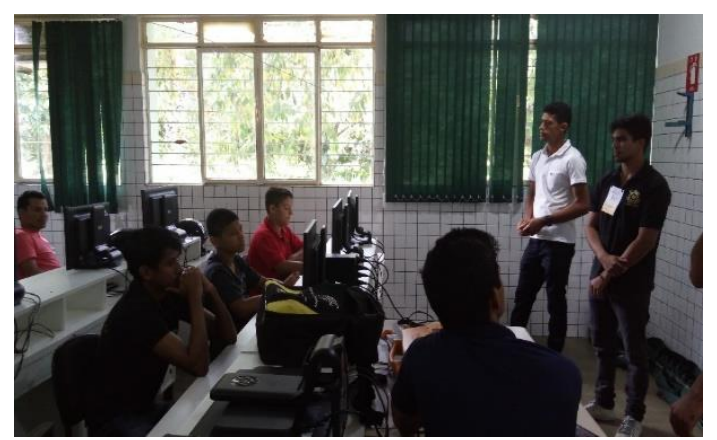

\section{Conclusões}

Após a elaboração deste trabalho, da análise da oficina de gênero textual charge e do conteúdo 
dos teóricos abordados nesta pesquisa, notou- se que a charge pode ser um ótimo instrumento facilitador de desenvolvimento de competências e habilidades de leitura não só na disciplina de Língua Portuguesa, mas em qualquer outra.

Em relação às produções individuais, a leitura concretizou- se melhor diante das orientações metodológicas, baseadas em mediações de construção e comparação, onde o aluno identificou o que realmente pretendia expor criticamente no seu texto.

Essa experiência teve ponto significativo não apenas para os participantes da oficina, mas também para o corpo de graduandos do curso de Licenciatura em Computação, pois trouxe conhecimentos práticos que proporcionarão boas práticas pedagógicas dentro da sala de aula proporcionando trocas de saberes e autonomia aos futuros docentes.

\section{Referências}

ARBACH, José Mtanios Isakandar. O fato gráfico: o humor gráfico como gênero jornalístico. São Paulo: USP/SP. Testes de doutoramento em Ciências da Comunicação, 2007.

MORAN, José Manuel; MASETTO, Marcos T.; BEHRENS, Marilda Aparecida. Novas tecnologias e mediação pedagógica. Campinas : Papirus, 2000.

PÉREZ GÓMEZ. A. I. As funções sociais da escola: da reprodução à reconstrução crítica do conhecimento e da experiência. In: SACRISTÁN, J. Gimeno. Compreender e transformar o ensino. 4 ed. Porto Alegre: Artmed, 1998.

REGO, Teresa Cristina. Vygotsky: Uma Perspectiva Histórico-Cultural da Educação. Petrópolis, RJ: Vozes, 1995.

ROMUALDO, Edson Carlos. Charge jornalística: polifonia e intextualidade. Maringá/PR: Eduem, 200.

SILVA, Ezequiel. T. Leitura na Escola e na Biblioteca. São Paulo: Papirus, 2004.

TEIXEIRA, Maria Cláudia. O gênero jornalístico charge no letramento escolar. Universidade Estadual do Centro-Oeste - Unicentro. v. 12. n. 19. p. 89-107, 2010. 